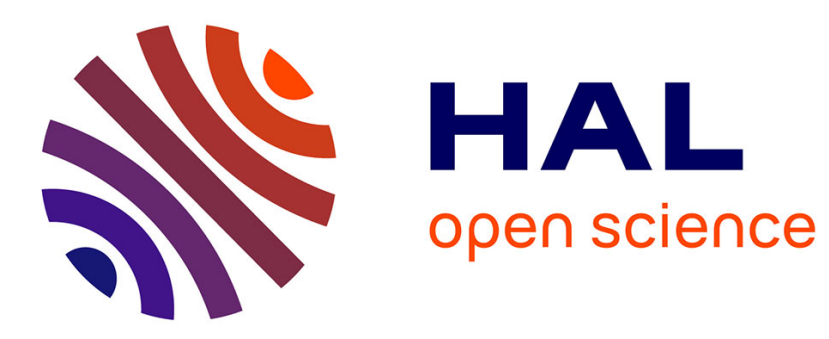

\title{
Influence of lexical markers on the production of contextual factors inducing irony
}

Elora Rivière, Maud Champagne-Lavau

\section{To cite this version:}

Elora Rivière, Maud Champagne-Lavau. Influence of lexical markers on the production of contextual factors inducing irony. 10th International and Interdisciplinary Conference on Modeling and Using Context (CONTEXT-17), Jun 2017, Paris, France. hal-01791892

\section{HAL Id: hal-01791892 \\ https://hal.science/hal-01791892}

Submitted on 15 May 2018

HAL is a multi-disciplinary open access archive for the deposit and dissemination of scientific research documents, whether they are published or not. The documents may come from teaching and research institutions in France or abroad, or from public or private research centers.
L'archive ouverte pluridisciplinaire HAL, est destinée au dépôt et à la diffusion de documents scientifiques de niveau recherche, publiés ou non, émanant des établissements d'enseignement et de recherche français ou étrangers, des laboratoires publics ou privés. 


\section{VERSION AUTEUR}

\section{Influence of lexical markers on the production of contextual factors inducing irony \\ Elora Rivière \& Maud Champagne-Lavau}

Aix Marseille Univ, CNRS, LPL, Aix-en-Provence, France

elora.rivieredlpl-aix.fr; maud.champagne-lavauduniv-amu.fr

\section{Introduction}

Previous research has suggested that contextual factors are required to lead to an ironic interpretation of an utterance. The highlighted contextual factors have been : the allusion to a failed expectancy, which is the fact to allude to a difference between previous expectations and the actual reality (Kumon-Nakamura, Glucksberg, \& Brown, 1995; Utsumi, 2000) ; view by others as the presence of an echo, the fact to mention a previous speech or events, thoughts, social norms or shared expectancies (Kreuz \& Glucksberg, 1989; Sperber \& Wilson, 1986). Another highlighted contextual factor is pragmatic insincerity, which is the violation of one or more felicity conditions in order to call the attention on the failed expectancy and express the speaker attitude towards this failure (Kumon-Nakamura et al., 1995; Utsumi, 2000). The two last factors are the expression of negative attitude, which can be described as the indirect expression of negative feelings about the failure of the expectancy (Utsumi, 2000) and specific to sarcasm, the presence of a victim (Utsumi, 2000). The victim of irony is an identifiable person or group of persons targeted by a negative comment. Campbell \& Katz (2012) were the first to experimentally test the necessity of these factors in the sarcastic interpretation of an utterance. They worked with the Constraints Satisfaction approach that allows the study of all these factors at the same time and the interaction between them. Indeed this approach suggests that the non-literal interpretation of an utterance would be precociously accessible only if the context (i.e., contextual factors) promoting this interpretation is substantial enough. The Constraints Satisfaction approach supposes that the several factors (i.e., called constraints in this approach) give a probabilistic base for a competitive interpretation in parallel and throughout the time. Some constraints then may be more likely to play a role early in the understanding process while others would play a later role. Within this framework, Campbell \& Katz (2012) reported that pragmatic insincerity is neither necessary nor sufficient, confirming the results of Colston (2000) about the non-necessity of the pragmatic insincerity. They also showed that none of these other contextual factors is necessary but each is sufficient in the comprehension of sarcasm. ${ }^{1}$

However Campbell \& Katz (2012) did not manipulate features of the target utterances such as ironic markers or type of irony. There is a distinction between factors (i.e., constraints) and markers of irony. Indeed, factors have to be present for an utterance to be qualify as ironic, without their presence an utterance is no longer ironic (Attardo, Eisterhold, Hay, \& Poggi, 2003). On the other hand, ironic markers (e.g., lexical markers) are defined as meta-communicative clues, helping but non essential in the comprehension of irony (Attardo, 2000). Burgers, van Mulken, \& Schellens (2012) showed that ironic markers such as lexical markers increase irony comprehension and reduce perceived complexity. In addition, the Implicit Display Theory (Utsumi, 2000) suggests that for an utterance to be understood as ironic, this utterance has to be embedded in an ironic environment and it implicitly displays this ironic environment. The lexical markers may contribute to implicitly display the ironic environment. Thus the role of lexical marker in the comprehension of an utterance as ironic seems to be sizeable.

The aim of the present study was to assess - in French - whether the presence of lexical markers influences the production of constraints inducing irony. According to this short literature review, the constraints tested were allusion to a failed expectancy, negative attitude and presence of a victim.

1 Sarcasm is a variable of verbal irony (Colston, 2000). Sarcasm is characterized by the factors characterizing verbal irony and added to them by the presence of a negative comment about an identifiable victim or a group of identifiable victims (Kumon-Nakamura, Glucksberg, \& Brown, 1995). 


\section{VERSION AUTEUR}

Our hypothesis was that if lexical markers influence the production of the factors, then the production of these factors should be more important when the ironic target utterance includes a lexical marker.

\section{Material and Method}

\subsection{Production task}

Twenty participants, 11 women and 9 men (mean age $=21.2$ years \pm 2.3 ; mean level of education $=15.1$ years \pm 2.0 ) were asked to complete 20 minimal contexts to induce an ironic interpretation of a target utterance (e.g., What beautiful weather).

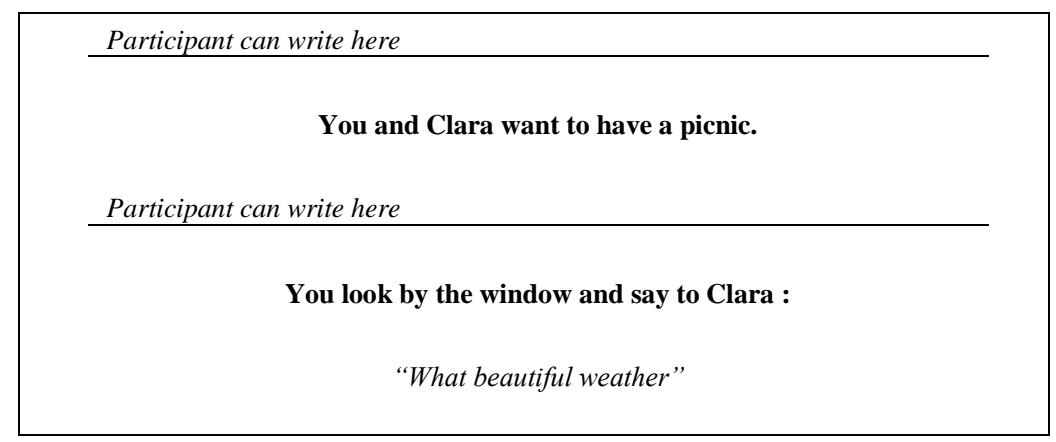

Fig. 1. Example of minimal context and target utterance as presented to participants

Target utterances were manipulated according to the type of verbal irony: with a victim, directed against someone (e.g., You are so fast) versus about a situation (e.g., What beautiful weather) and according to the presence (e.g., What beautiful weather) vs. absence (e.g., It is useful) of a lexical marker leading to the 4 following conditions: irony with a victim and presence of a lexical marker; irony with a victim without the presence of a lexical marker; irony about situation with presence of a lexical marker; and irony about a situation without the presence of a lexical marker. There were five target utterances for each of the four conditions.

\subsection{Target utterances validation}

Before the task of context production, the target utterances were validated by another group of participants containing 22 women and 22 men (mean age $=24.9 \pm 2.4$; mean level of education $=15.9 \pm 1.4$ ). The purpose of this validation, done on 35 utterances, was to select 20 utterances that can be equally understood as sincere and as ironic to ensure that if a target utterance was judged as ironic after the step of context completion, it was due to the constraints added by the participants and not due to the target utterances themselves. To achieve this validation, the participants were asked to evaluate, on a seven points Likert scale, the use frequency of each utterance as sarcastic. The utterances that obtained a middle score between 2.5 and 4.5 were selected.

\section{Results}

The 400 contexts were produced and then judged as ironic or not. In a second step, the 300 stimuli recognized as ironic were analyzed for the presence of each contextual factor (i.e., allusion to a failed expectancy, negative attitude and presence of a victim). Two types of irony (with victim or about a situation) x 2 lexical markers (presence or absence) repeated-measure ANOVAs were performed on the percentage of stimuli containing each pragmatic constraint (presence of a victim, negative tension and allusion to a failed expectancy).

The $2 \times 2$ ANOVA on the percentage of stimuli containing the factor presence of a victim results showed a main effect of the lexical marker on the percentage of stimuli containing the contextual factor presence of a victim $(\mathrm{F}(1.18)=12.426 ; \mathrm{p}=0.002)$ meaning that when the lexical marker was present $(\mathrm{M}=41.83 \%)$, less stimuli 


\section{VERSION AUTEUR}

were produced with the contextual factor presence of a victim than when it was absent $(\mathrm{M}=53.03 \%)$. It also showed a main effect of the type of irony $(\mathrm{F}(1.18)=253.349 ; \mathrm{p}<0.0001)$ meaning that the irony with a victim $(\mathrm{M}$ $=85.66 \%$ ) contains a percentage more important of stimuli including this factor than irony about a situation (M $=9.20 \%$ ). The interaction type of irony $x$ lexical marker was no significant: $F(1.18)=3.906 ; p=0.064$.

A main effect of lexical marker was also shown by the $2 \times 2$ ANOVA on the percentage of stimuli containing the factor negative attitude $(\mathrm{F}(1.18)=44.032 ; \mathrm{p}<0.0001)$ meaning that when the lexical marker was present $(\mathrm{M}$ $=91.36 \%$ ) in the target sentence, more stimuli were produced with the contextual factor negative attitude than when it was absent $(\mathrm{M}=69.39 \%)$ (see Figure 2). This ANOVA also showed a main effect of the irony type $\mathrm{F}$ $(1.18)=33.312 ; \mathrm{p}<0.0001$. Indeed, the percentage of stimuli including the factor negative attitude is more important when the stimuli belong to the type irony about a situation $(\mathrm{M}=91.45 \%)$ than when they belong to the type irony with a victim $(\mathrm{M}=69.30 \%)$. The interaction type of irony $\mathrm{x}$ lexical marker was not significant $(\mathrm{F}(1.18)=$ $2.602 ; \mathrm{p}>0.05)$.

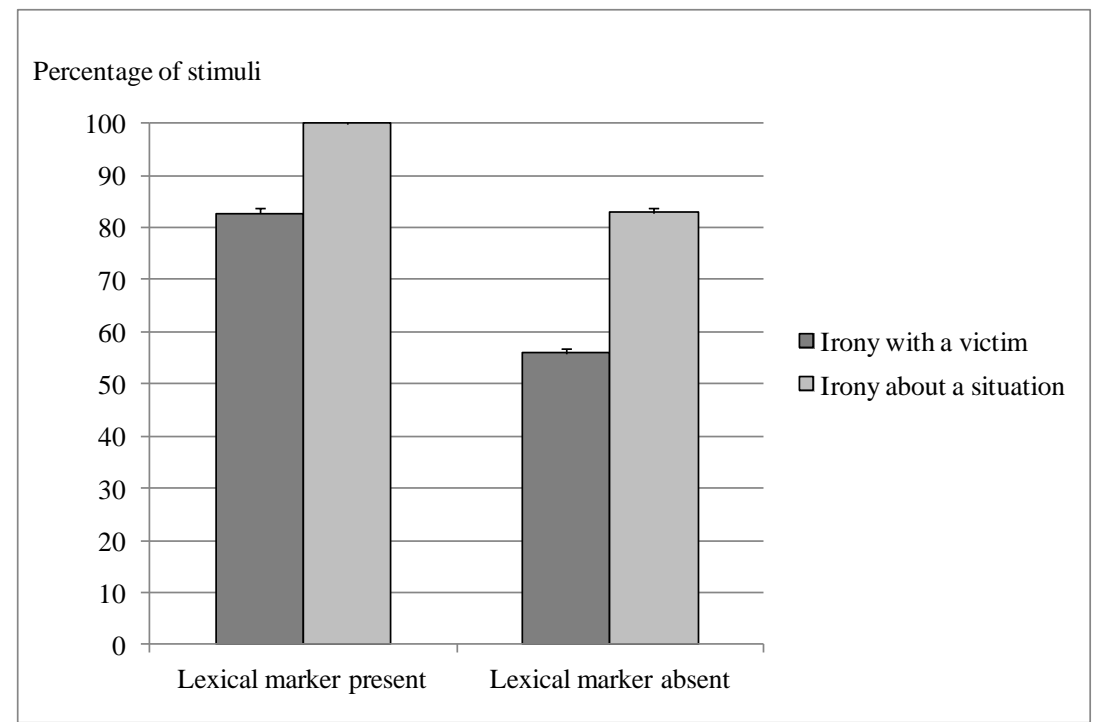

Fig. 2. Percentage of stimuli containing the factor negative attitude in function of the presence or absence of the lexical marker in the target utterances and of the type of irony.

The $2 \times 2$ ANOVA on the percentage of stimuli containing the factor allusion to a failed expectancy showed no significant effect of the lexical marker $F(1.18)=3.588 ; p=0.074$. It did not show any significant effect of the type of irony $(\mathrm{F}(1.18)=1.613 ; \mathrm{p}>0.05)$. The interaction type of irony $\mathrm{x}$ lexical marker didn't reach significance: $\mathrm{F}(1.18)=1.124 ; \mathrm{p}>0.05$.

\section{Discussion}

The results showed that the presence of a lexical marker in the target utterance influences the production of factors presence of a victim and negative attitude but does not influence the production of the factor allusion to a failed expectancy.

The fact that lexical markers are often hyperbolic and thus invite to an increase of the negative feeling most likely explains the results obtained for the factor negative attitude. Indeed our results showed that the factor negative attitude was more present when the ironic target utterance includes a lexical marker than when the lexical marker is absent of the target utterance. These results are in agreement with the Implicit Display Theory (Utsumi, 2000). The linked made by Utsumi (2000) between negative attitude and the presence of lexical marker in the ironic target utterance can effectively be confirmed by our results. 


\section{VERSION AUTEUR}

By contrast, the pragmatic constraint presence of a victim was more present when the ironic target utterance did not include a lexical marker than when it included a lexical marker. There is no literature about the influence of lexical marker on the presence of a victim but maybe these results could be explained by the Constraints Satisfaction approach. Indeed, this approach considers that no constraint is necessary but that they are sufficient to reach a stable state, in this case the comprehension of the utterance as ironic or as sincere. Due to the influence of the presence of a lexical marker on the production of the factor negative attitude, this factor would be stronger and may play a precocious role. In consequence, the role played by the factor presence of a victim would be undermined in the presence of a lexical marker. More research should be necessary to confirm this hypothesis.

No effect of the lexical marker has been found on the factor allusion to a failed expectancy. These results could be explained by the fact that the constraint allusion to a failed expectancy is the more present constraint in the ironic utterances. It could be possible that its role in context to the comprehension of irony is so strong that its production is not influenced by linguistic constraint specific to the ironic target utterance. Allusion to failed expectancy (Kumon-Nakamura et al., 1995; Utsumi, 2000), or view by others as the presence of an echo (Kreuz \& Glucksberg, 1989; Sperber \& Wilson, 1986), seems to be the constraint whose role, played in the comprehension of an utterance as ironic, makes the most consensus in the literature. The sizeable role of this factor is reflected by the authors' agreement and is probably the reason why the presence or absence of a lexical marker did not influence the production of this factor.

Our results seemed to show that the different features as factors and ironic markers as lexical markers play intermingled roles in irony processing.

As a conclusion, features of the ironic utterances such as the presence of a lexical marker could have an influence on the production of the factors present in the context and whose role is to induce an ironic interpretation of the utterance. Until now, the various features (i.e., factors and ironic markers as lexical markers) playing a role in irony processing have been studied separately but our results highlighted the need to study all types of features at the same time and in interactions. It will be very interesting, using the Satisfaction Constraint approach to evaluate the weight of each factor and to see if some ironic markers as the presence of a lexical marker have an influence on this weight. Moreover, the influence, on the production of factors, of other types of features such as the sociological ones, whose role on irony processing have been shown (Gibbs, 2000; Ivanko, Pexman, \& Olineck, 2004) should also be taken into account. 


\section{VERSION AUTEUR}

\section{References}

1. Attardo, S. (2000). Irony markers and functions: Towards a goal-oriented theory of irony and its processing. Rask, 12, 3-20.

2. Attardo, S., Eisterhold, J., Hay, J., \& Poggi, I. (2003). Multimodal markers of irony and sarcasm. Humor - International Journal of Humor Research, 16(2), 243-260.

3. Burgers, C., van Mulken, M., \& Schellens, P. J. (2012). Type of evaluation and marking of irony: The role of perceived complexity and comprehension. Journal of Pragmatics, 44(3), 231-242.

4. Campbell, J. D., \& Katz, A. N. (2012). Are there necessary conditions for inducing a sense of sarcastic irony? Discourse Processes, 49:6, 459-480.

5. Colston, H. L. (2000). On necessary conditions for verbal irony comprehension. Pragmatics and Cognition, (8), 277324.

6. Gibbs, R. W., Jr. (2000). Irony in talk among friends. Metaphor and Symbol, (15), 5-27.

7. Ivanko, S. L., Pexman, P. M., \& Olineck, K. M. (2004). How sarcastic are you ? Individual Differences and Verbal Irony. Journal of Language and Social Psychology, (23(3)), 244-271.

8. Kreuz, R. J., \& Glucksberg, S. (1989). How to be sarcastic: The echoic reminder theory of verbal irony. Journal of experimental Psychology: General, 118(4), 374-386.

9. Kumon-Nakamura, S., Glucksberg, S., \& Brown, M. (1995). How about another piece of pie : the allusional pretense theory of discourse irony. Journal of experimental Psychology: General, 124(1), 3-21.

10. Sperber, D., \& Wilson, D. (1986). Relevance: Communication and cognition.

11. Utsumi, A. (2000). Verbal irony as implicit display of ironic environment: distinguishing ironic utterances from nonirony. Journal of Pragmatics, 32, 1777-1806. 